\title{
Association between air pollution, body mass index, respiratory symptoms, and asthma among adolescent school children living in Delhi, India
}

\author{
Sundeep Santosh Salvi', Abhishek Kumar', Harshavardhan Puri', Sukhram Bishnoi ${ }^{2}$, Belal Bin Asaf, \\ Deesha Ghorpade ${ }^{1}$, Sapna Madas ${ }^{1}$, Anurag Agrawal ${ }^{3}$, Arvind Kumar ${ }^{2}$ \\ ${ }^{1}$ Pulmocare Research and Education (PURE) Foundation, Pune, Maharashtra, India, ${ }^{2}$ Lung Care Foundation, New Delhi, India, \\ ${ }^{3}$ CSIR Institute of Genomics and Integrative Biology, New Delhi, India
}

\section{ABSTRACT}

Background: Delhi is one of the most polluted cities in the world with annual average ambient $\mathrm{PM}_{10}$ and $\mathrm{PM}_{2.5}$ levels exceeding the World Health Organization standards by over 15 fold. We aimed to study the prevalence of respiratory and allergic symptoms and asthma among adolescent children living in Delhi (D) and compare it with children living in lesser polluted cities of Kottayam (K) and Mysore (M) located in Southern India. Methods: 4361 boys and girls between the age group of 13-14 and 16-17 years from 12 randomly selected private schools from $D, K$, and $M$ were invited to participate. Modified and expanded International Study for Asthma and Allergies in Children (ISAAC) questionnaires (Q) were filled by the students who also performed spirometry using the ultrasonic flow-sensor-based nDD Spirometer. Results: 3157 students (50.4\% boys) completed the $Q$ and performed good quality spirometry. The prevalence of asthma and airflow obstruction among children living in Delhi was $21.7 \%$ using the ISAAC Q and $29.4 \%$ on spirometry, respectively. This was accompanied by significantly higher rates of self-reported cough, shortness of breath, chest tightness, sneezing, itchy and watery eyes, itchy skin, and eczema among Delhi children (vs. K-M, all $P<0.05$ ). Delhi children were more overweight and obese $(39.8 \%$ vs. $16.4 \%, P<0.0001)$, and this was the only risk factor that was strongly associated with asthma (odds ratio [OR]: 1.79; confidence interval: 1.49-2.14), with a more pronounced effect in Delhi children $(P=0.04)$. Forced expiratory volume ${ }_{1}$ and Forced vital capacity values were significantly higher in Delhi children (vs. K-M $P<0.0001)$. Preserved ratio impaired spirometry was more common in K-M children $(P<0.0001)$. Conclusion: Adolescent children living in the polluted city of Delhi had a high prevalence of asthma, respiratory symptoms, allergic rhinitis, and eczema that was strongly associated with a high body mass index (BMI). Our study suggests an association between air pollution, high BMI, and asthma/allergic diseases, which needs to be explored further.

KEY WORDS: Air pollution, asthma, respiratory symptoms, spirometry

Address for correspondence: Dr. Sundeep Santosh Salvi, Pulmocare Research and Education Foundation, FAITH Centre, $1^{\text {st }}$ Floor, Sakorenagar,

Viman Nagar, Pune - 411 014, Maharashtra, India. E-mail: ssalvi@purefoundation.in

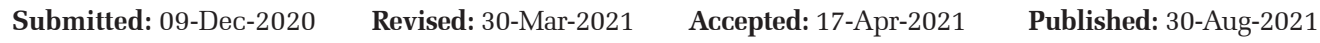

\begin{tabular}{|l|l|}
\hline \multicolumn{2}{|c|}{ Access this article online } \\
\hline Quick Response Code: & Website: \\
\hline & www.lungindia.com \\
\hline & \\
\hline
\end{tabular}

This is an open access journal, and articles are distributed under the terms of the Creative Commons Attribution-NonCommercial-ShareAlike 4.0 License, which allows others to remix, tweak, and build upon the work non-commercially, as long as appropriate credit is given and the new creations are licensed under the identical terms.

For reprints contact: WKHLRPMedknow_reprints@wolterskluwer.com

How to cite this article: Salvi SS, Kumar A, Puri H, Bishnoi S, Asaf BB, Ghorpade D, et al. Association between Air Pollution, Body Mass Index, Respiratory Symptoms, and Asthma among Adolescent School Children living in Delhi, India. Lung India 2021;38:408-15.

(C) 2021 Indian Chest Society | Published by Wolters Kluwer - Medknow 


\section{INTRODUCTION}

Delhi, India's national capital region with a population of over 30 million is one of the most polluted cities on the earth. Growing number of motor vehicles, presence of coal-powered power plants in the vicinity, growing construction sites, and burning of crop stubble in the neighboring cities, supported by weather and wind conditions have contributed to very high levels of ambient air pollution in Delhi. ${ }^{[1]}$ In 2019, Delhi's annual average PM $_{10}$ levels were between 154 and $217 \mu \mathrm{g} / \mathrm{m}^{3}$ and $\mathrm{PM}_{2.5}$ levels between 79 and $128 \mu \mathrm{g} / \mathrm{m}^{3}{ }^{3}{ }^{[2]}$ levels which are over 15 -times higher than the World Health Organization (WHO) standards. Public health emergencies have been declared many times, and several dramatic measures have been undertaken, such as odd-even travel schemes, shutting down of 6000 schools, total ban on all trucks entering the city, ban on burning fire crackers during the Diwali festival, temporary shutdown of construction sites, and closure of neighboring coal-powered plants, yet all these have had little impact on quality of air that residents of Delhi breathe. ${ }^{[3]}$

Children are one of the most vulnerable population to the harmful effects of air pollution and serious concerns have been raised about the lung health of over 6 million children living in Delhi. Children breathe greater volumes of air than adults and many of the pollutants in the inhaled air interfere with the proper growth and development of the lungs. ${ }^{[4]}$ Chronic exposure to high levels of air pollution has been shown to be associated with a greater risk of developing respiratory tract infections, asthma, ${ }^{[5-7]}$ and stunted lung growth. ${ }^{\left[{ }^{[8]}\right.}$ More recently, air pollution and some of its obesogenic components have been shown to be associated with the development of obesity, which further contributes to the development of asthma in children. ${ }^{[9]}$ Spirometry values in healthy children from Delhi have been shown to be around 10\% lower than the equivalent Caucasian children. ${ }^{[10]}$ Few studies have examined the adverse health effects of air pollution in children living in Delhi and most of these have used only questionnaire-based approaches with very little emphasis on objective measurements of lung function.

India is a large and heterogeneous country with varying cultures, food habits, lifestyles, and living conditions. Air pollution levels in India are higher in the northern region, while the southern parts of India are relatively less polluted. Kottayam is an urban sea city in the south-western region of India in the state of Kerala with a population of 136,000. It is known for its vast paddy fields and rubber trees. Mysore is another urban city in South India in the state of Karnataka located at $740 \mathrm{~m}$ above sea level with a population of 920,000. The annual average $\mathrm{PM}_{10}$ levels in Kottayam and Mysore are around $40-50 \mu \mathrm{g} / \mathrm{m}^{3}$ and $\mathrm{PM}_{2.5}$ between 15 and $30 \mu \mathrm{g} / \mathrm{m}^{3} \cdot{ }^{[2]}$

We hypothesized that children living in Delhi will have a greater prevalence of respiratory symptoms, asthma, and allergic diseases and will have worse lung function values measured by spirometry, as compared to children living in Kottayam and Mysore.

\section{Study design}

This cross-sectional, case-control study was conducted in the cities of Delhi (case) and Kottayam and Mysore (controls) in India. Adolescent school children studying in standards $8^{\text {th }}$ and $11^{\text {th }}$ (i.e. children between the age group of 13-14 and 16-17 years) were chosen as the study population because ${ }^{[1]}$ this age is close to reaching the peak adult lung function, ${ }^{[2]}$ children at this age are old enough to understand and fill the study questionnaire properly, ${ }^{[3]}$ changes in sex hormones during this age may have differential effects on lung function, and ${ }^{[4]}$ they would be more co-operative to perform good quality spirometry.

The sample size for the study was estimated based on the prevalence of expected childhood asthma in Delhi. Using a prevalence rate of $10 \%$, an absolute precision of $2 \%$, and the desired confidence level of 95\%, the calculated sample size was 857 . Considering a dropout rate of $20 \%$, the final calculated sample size was 1071 for each of the three cities.

We chose to conduct the study only among students from private schools because we wanted to minimize the confounding caused by low socioeconomic class, under-nutrition, overcrowding, and indoor air pollution, risk factors that are relatively common in children studying in public schools, which are known to be strongly associated with asthma. We randomly selected co-ed schools that had both age groups. The aim was to get a total of around 1000 children with roughly equal number of boys and girls from each city. The study was approved by the Ethics Committee of Sir Gangaram Hospital, Delhi (Ref No: EC/07/19/1556), where authors 3.4.5.and 9 worked.

We then identified doctors in Delhi, Kottayam, and Mysore, who were members of the Doctors for Clean Air Campaign to lead the study in their respective cities. They helped in randomly selecting private co-ed schools, getting the requisite permissions from the school Principals and teachers after explaining to them the purpose of the study and finally ensuring proper conduct of the operational part of the study. To reach the appropriate sample size of 1000 for each city, we had to select three schools from Delhi, six schools from Kottayam, and three schools from Mysore.

\section{Training of the study team}

We formed a team comprising of 4 doctors/supervisors, 7 spirometry technicians, and 6 nurses for the uniform administration of the study questionnaires, measuring height and weight and performing standardized spirometry. The entire study team traveled to all the 3 cities and stayed there until the completion of the study. All the study team members underwent training for 7 days at the Chest Research Foundation (CRF), Pune, India, where they learnt the art and science of conducting good quality 
spirometry using the ATS/ERS 2005 guidelines. ${ }^{[11]}$ Several practice runs were undertaken to ensure the performance of good quality spirometry (Grade A/B) in at least $80 \%$ of the tested subjects.

After the school principals gave permission, the study team met the class teachers and explained them the purpose and objective of the study. Students were handed the study-related questionnaire and information sheet to take home and were asked to obtain their parents/guardians written consent if they agreed for their child/ward to participate in the study. The questionnaire was mostly based on the International Study for Asthma and Allergies in Children (ISAAC) questionnaire with a few more additions to include more local risk factors for asthma. Those children who obtained written consent filled in the questionnaires either themselves or with the help of their parents or field workers and submitted it to the study team who ensured that all the questions were filled appropriately.

Height and weight were measured in the classes. Pre-bronchodilator spirometry was performed using the nDD spirometer (Easy one ${ }^{\circledR}$ Air, Switzerland) after the procedure was explained and demonstrated by the study team. Between three and eight blows were obtained from each student. The reports and graphs were uploaded and submitted the same day to the CRF team where quality assurance of spirometry was performed by an independent team of experts. Poor quality tests were repeated the next day. Only good quality spirometry graphs were included in the analysis. Predicted values from the Global Lung Index 2012 were used as reference equation. The body mass index (BMI) was classified according to the Indian published guidelines ${ }^{[12]}$ for adolescents as: Underweight: $<18.5 \mathrm{~kg} / \mathrm{m}^{2}$; normal: $18.5-23 \mathrm{~kg} / \mathrm{m}^{2}$; overweight: $23-27 \mathrm{~kg} / \mathrm{m}^{2}$; and obese: $>27 \mathrm{~kg} / \mathrm{m}^{2}$.

Data management and statistical analysis

Data stored in the spirometer were directly transferred to the excel sheet clubbed with the subject's unique ID. Data transfer from the questionnaire to the excel sheet was performed using double data entry at the study co-ordinating center in Delhi. Discordant data were rectified by mutual consent after re-checking the raw data. Only acceptable spirometry graphs and properly filled in questionnaires were included. Clean data were locked for the analysis.

Simple descriptive analysis was performed to obtain the prevalence rates for different symptoms and diseases. The continuous variables were presented using $\mathrm{N}$, mean \pm standard deviation or median (interquartile ranges). Associations between the variables were analyzed using $\lambda^{2}$ test to obtain odds ratio and confidence intervals (CIs). Unadjusted $P<0.05$ was considered significant to account for multiple comparison and results were expressed as adjusted odds ratios and CIs. The comparison of symptom prevalence between Delhi (D) and Kottayam $(\mathrm{K})+$ Mysore $(\mathrm{M})$ was performed using 2-sample proportion tests. The spirometry data included were forced expiratory volume ${ }_{1}\left(\mathrm{FEV}_{1}\right)$, (\%predicted), forced vital capacity (FVC) (\%predicted), and $\mathrm{FEV}_{1} / \mathrm{FVC}$. airflow obstruction was defined as $\mathrm{FEV}_{1} / \mathrm{FVC}<0.85$. The ISAAC Questionnaire-defined asthma was based on the presence of any of the three answers: Physician diagnosed asthma, current wheeze (last 3 months or last 12 months) or current use of asthma treatment. All statistical analysis tests were performed using the SPSS Version 22 (IBM Singapore), December 2013. The significance levels of all statistical tests were expressed as $P$ values. The results were presented using the appropriate tables and graphs.

\section{RESULTS}

A total of 4361 boys and girls from 12 schools (3 Delhi, 6 Kottayam, and 3 Mysore) were invited to participate in this study, of which 3456 consented (response rate 79.2\%) and 928 students from Delhi (55\% Boys), 1040 from Kottayam (40\% Boys), and 1189 from Mysore (58.4\% Boys), completed the questionnaire and performed good quality spirometry [Supplementary Table 1].

The demographic details of the students are given in Table 1. Although the children from D were younger than K-M by 2 months, they were significantly taller $(P<0.0001)$ and heavier $(P<0.0001)$ and had a significantly higher BMI (D: $22.1 \pm 4.6$ vs. $19.5 \pm 3.8 ; P<0.0001$ ) [Table 1]. The prevalence of overweight and obesity in children from $\mathrm{D}$ and K-M was $39.8 \%$ and $16.4 \%$, respectively $(P<0.0001)$. In the total study population (D + K-M), children who were overweight/obese had significantly greater odds of having spirometrically defined airflow obstruction (odds ratio [OR]: 1.79 CI: 1.49-2.14; $P<0.0001$ ). Overweight/obese children living in Delhi had greater odds of having spirometrically defined airflow obstruction than overweight/obese children from K-M (OR: $1.38 \mathrm{CI}$ : 1.01-1.87; $P=0.04$ ).

The prevalence rates of cough, shortness of breath, chest pain/tightness, blocked nose, sneezing, itchy watery eyes, eczema, and itchy skin were reported to be significantly higher in children living in Delhi [Table 2A and Figure 1a-c].

When asthma was defined using the ISAAC questionnaire, there was no difference in the prevalence rates between children living in D and K-M (21.7\% vs. 21.5\%; $P=$ ns) [Supplementary Table 2]. However, when spirometry was used to define airflow obstruction/asthma, the prevalence of asthma was significantly higher among children living in Delhi than K-M (29.4\% vs. 22.6\%; $P<0.0001$ ) [Supplementary Table 2]. We clubbed spirometry defined airflow obstruction asthma ( $\mathrm{S}+\mathrm{ve}$ ) and ISAAC $\mathrm{Q}$ defined asthma ( $\mathrm{Q}+\mathrm{ve})$ and found that the proportion of children who had nonobstructive spirometry and no respiratory symptoms was significantly lower in Delhi compared to $\mathrm{K}-\mathrm{M}$ (57.2\% vs. $62.6 \% ; P=0.004$ ) [Figure 2]. $8.3 \%$ of 
Table 1: Demographic details and potential risk factors associated with asthma (Delhi vs. Kottayam-Mysore)

\begin{tabular}{lccc}
\hline & Delhi $(\boldsymbol{n}=\mathbf{9 2 8}) \mathbf{( \% )}$ & Kottayam-Mysore $(\boldsymbol{n}=\mathbf{2 2 2 9}) \mathbf{( \% )}$ & Delhi versus Kottayam-Mysore $(\boldsymbol{P})$ \\
\hline Boys & 54.5 & 48.8 & 0.003 \\
Age $($ years), mean \pm SD & $14.4 \pm 1.7$ & $14.7 \pm 1.6$ & $<0.0001$ \\
Height $(\mathrm{cm})$, mean \pm SD & $162.8 \pm 9.8$ & $158.3 \pm 10.4$ & $<0.0001$ \\
Weight $(\mathrm{kg})$, mean \pm SD & $58.8 \pm 14.9$ & $49.9 \pm 12.01$ & $<0.0001$ \\
BMI $\left(\mathrm{kg} / \mathrm{m}^{2}\right)$ & $22.09 \pm 4.59$ & $19.49 \pm 3.86$ & $<0.0001$ \\
Underweight $(<18.5)$ & 23.10 & 45.20 & $<0.0001$ \\
Normal $(18.5-23)$ & 37.20 & 38.40 & 0.527 \\
Over weight $(23-27)$ & 25.10 & 11.90 & $<0.0001$ \\
Obese $(>27)$ & 14.70 & 4.50 & $<0.0001$ \\
Caesarean delivery & 34.6 & 29.3 & 0.004 \\
Vegetarian diet & 46.3 & 26.40 & $<0.0001$ \\
Presence of pets at home & 13.1 & 27.9 & $<0.0001$ \\
Family history of asthma/allergy & 29.8 & 33.7 & 0.03 \\
Smoker in the family & 13.9 & 18.8 & 0.001 \\
Presence of separate kitchen & 92.5 & 88.3 & $<0.0001$ \\
Home with $\leq 2$ bedroom & 25.5 & 48.90 & $<0.0001$ \\
Use of mosquito coil & 62.2 & 61.0 & 0.541 \\
Use of incense stick & 52.5 & 52.0 & 0.805 \\
Use of dhoop incense & 54.8 & 32.2 & $<0.0001$ \\
Distance of school from home $(\mathrm{km})$ & & & $<0.0001$ \\
<5 & 67.6 & 48.5 & \\
\hline
\end{tabular}

SD: Standard deviation

Table 2A: Comparison of self-reported prevalence of respiratory and allergic symptoms between children living in Delhi and children living in Kottayam-Mysore

\begin{tabular}{|c|c|c|c|c|}
\hline Symptoms & Delhi $(n=928)(\%)$ & Kottayam-Mysore $(n=2229)(\%)$ & OR (CI) & $P$ \\
\hline \multicolumn{5}{|l|}{ Last 3 months } \\
\hline Cough & 50.9 & 35.4 & $1.88(1.61-2.20)$ & 0.001 \\
\hline Shortness of breath & 9.7 & 4.5 & $2.29(1.70-3.08)$ & $<0.0001$ \\
\hline Chest pain & 9.1 & 3.5 & $2.67(1.95-3.66)$ & $<0.0001$ \\
\hline Wheeze & 4.2 & 3.3 & $1.30(0.87-1.93)$ & 0.199 \\
\hline Running nose & 27.0 & 25.1 & $1.10(0.93-1.31)$ & 0.271 \\
\hline Blocked nose & 33.4 & 29.8 & $1.18(1.00-1.39)$ & 0.048 \\
\hline \multicolumn{5}{|l|}{ Last 12 months } \\
\hline Cough & 38.4 & 18.9 & $2.67(2.25-3.16)$ & $<0.0001$ \\
\hline Shortness of breath & 31.5 & 10.8 & $3.77(3.11-4.57)$ & $<0.0001$ \\
\hline Chest tightness & 11.2 & 4.7 & $2.53(1.91-3.35)$ & $<0.0001$ \\
\hline Wheeze & 18.6 & 17.9 & $1.05(0.86-1.27)$ & 0.665 \\
\hline Itchy rash & 33.0 & 12.1 & $3.56(2.95-4.28)$ & $<0.0001$ \\
\hline Eczema & 8.7 & 1.8 & $5.09(3.47-7.48)$ & $<0.0001$ \\
\hline Itchy watery eyes & 44.9 & 28.8 & $9.74(1.56-2.48)$ & $<0.0001$ \\
\hline Sneezing & 52.8 & 39.3 & $1.74(1.49-2.03)$ & $<0.0001$ \\
\hline
\end{tabular}

OR: Odds ratio, CI: Confidence interval

children from Delhi were S + ve and Q + ve, compared to $7.6 \%$ from Kottayam and 6.1\% from Mysore. $34.5 \%$ of children from Delhi were either $\mathrm{S}+$ ve and $\mathrm{Q}-$ ve or $\mathrm{S}-\mathrm{ve}$, $\mathrm{Q}+$ ve compared to $28.1 \%$ from Kottayam and $32.8 \%$ from Mysore [Figure 2].

Children from Delhi had significantly higher FEV $_{1}$ and FVC values (expressed as both \%predicted and Z-scores) but similar $\mathrm{ZFEV}_{1} / \mathrm{FVC}$ values. The prevalence of preserved ratio, impaired spirometry (PRISm), defined as $\mathrm{FEV}_{1} / \mathrm{FVC}>0.85$, FVC $<80 \%$ predicted or $\mathrm{FEV}_{1}<80 \%$ predicted) which indicates a restrictive spirometry pattern was significantly higher in children from K-M [Table 2B for all results].

While children living in Delhi were more likely to be born by cesarean delivery $(P=0.004)$ and burn dhoop (incense) at home $(P<0.0001)$, children from K-M were more likely to have a family history of asthma or allergies $(P=0.03)$, have a smoker in the family $(P=0.001)$, live in a home that had $\leq 2$ bedrooms $(P<0.0001)$, have a pet at home $(P<0.0001)$ and live $>5 \mathrm{Kms}$ from the school $(P<0.0001)$ [Table 1]. However, none of these risk factors showed any associations with asthma prevalence.

Out of the $29.3 \%$ children who were found to have airflow obstruction/asthma on spirometry in Delhi, only $12 \%$ reported ever being diagnosed with asthma and $3.3 \%$ were using some form of inhalers. In K-M, among the $22.5 \%$ children who were found to have airflow obstruction/asthma on spirometry, $27 \%$ reported ever being diagnosed asthma and 8\% were using some inhalers. 
Table 2B: Comparison of spirometry values between children living in Delhi and children living in Kottayam-Mysore

\begin{tabular}{|c|c|c|c|}
\hline & Delhi & Kottayam-Mysore & $P$ \\
\hline $\mathrm{FEV} \%$ prediction $($ mean $\pm \mathrm{SD})$ & $90 \pm 11.8$ & $86.2 \pm 14.1$ & $<0.0001$ \\
\hline $\mathrm{FVC} \%$ prediction $(\operatorname{mean} \pm \mathrm{SD})$ & $92.2 \pm 12.0$ & $88 \pm 14.3$ & $<0.0001$ \\
\hline $\begin{array}{l}\mathrm{FEV}_{1} / \mathrm{FVC} \% \text { prediction } \\
\left(\mathrm{mean}^{\prime} \mathrm{SD}\right)\end{array}$ & $87.7 \pm 6.3$ & $88.7 \pm 5.8$ & $<0.0001$ \\
\hline $\mathrm{FEV}_{1} / \mathrm{FVC}<0.85(\%)$ & 29.4 & 22.6 & $<0.0001$ \\
\hline $\mathrm{zFEV}_{1}(\operatorname{mean} \pm \mathrm{SD})$ & $-0.86 \pm 1.02$ & $-1.29 \pm 1.34$ & $<0.0001$ \\
\hline zFVC (mean \pm SD) & $-0.67 \pm 1.02$ & $-1.09 \pm 1.22$ & $<0.0001$ \\
\hline $\mathrm{zFEV}_{1} / \mathrm{FVC}($ mean $\pm \mathrm{SD})$ & $-0.38 \pm 1.05$ & $-0.33 \pm 1.0$ & NS \\
\hline \multicolumn{4}{|l|}{$\mathrm{FEV}_{1} / \mathrm{FVC}>0.85$} \\
\hline $\mathrm{FEV}_{1}<80 \%$ & 13.7 & 28.3 & $<0.0001$ \\
\hline $\mathrm{FVC}<80 \%$ & 12 & 22 & $<0.0001$ \\
\hline $\mathrm{FEV}_{1}$ and $\mathrm{FVC}<80 \%$ & 2.5 & 5.8 & $<0.0001$ \\
\hline
\end{tabular}

FEV : Forced expiratory volume ${ }_{1}$ FVC: Forced vital capacity, NS: Not significant, ZFEV: Z-scores of forced expiratory volume, SD: Standard deviation
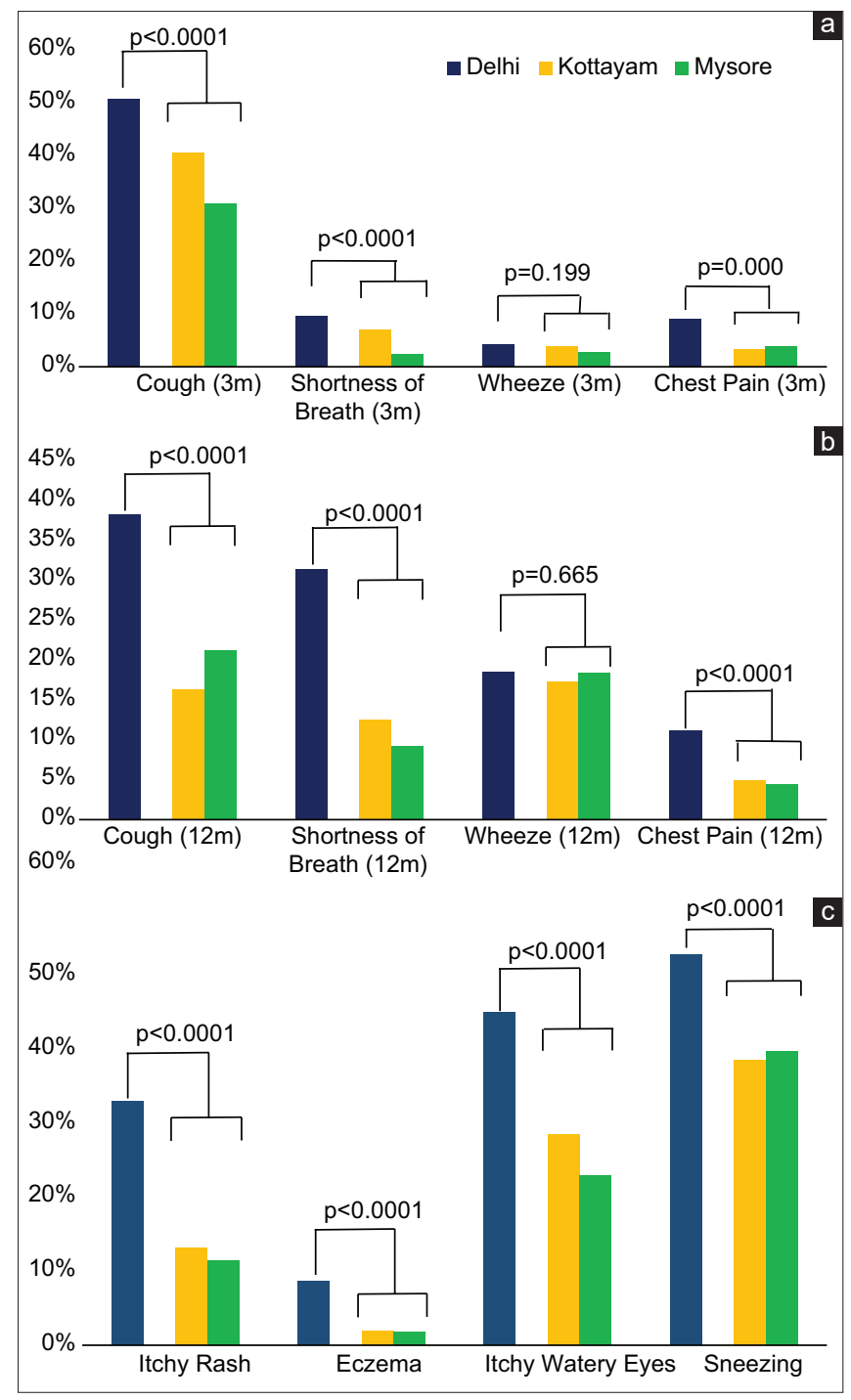

Figure 1: (a) Differences in the prevalence of symptoms between $D$ and $\mathrm{K} \mathrm{M}$ during the last 3 months. (b) Differences in the prevalence of symptoms between $\mathrm{D}$ and $\mathrm{KM}$ during the last 12 months. (c) Differences in the prevalence of allergic symptoms between $\mathrm{D}$ and $\mathrm{K} \mathrm{M}$

\section{DISCUSSION}

Adolescent children living in the polluted city of Delhi had a very high prevalence of asthma $(21.7 \%$ on ISAAC $Q$ and 29.4\% airflow obstruction on Spirometry), self-reported allergic rhino-conjunctivitis and eczema accompanied by higher prevalence rates of cough, shortness of breath, and chest pain/tightness as compared to children living in the lesser polluted cities of Kottayam and Mysore. Over 50\% of children living in Delhi complained of cough during the last 3 months, while shortness of breath was reported by over 30\% children during the previous 12 months. Boys had a significantly higher prevalence of asthma than girls in all three cities. Children living in Delhi were significantly more overweight/obese and this was the only risk factor that was strongly associated with asthma in $\mathrm{D}$ as well as K-M, but the effect was more pronounced in Delhi children. The two lung volumes $\left(\mathrm{FEV}_{1}\right.$ and $\left.\mathrm{FVC}\right)$ were significantly higher in Delhi children, but so was airflow obstruction. PRISm, which indicates a restrictive lung component, was more common in children living in K-M.

The three key novel observations made in this study are as follows: (a) Children living in the polluted city of Delhi were overweight and obese which was strongly associated with airflow obstruction/asthma defined on spirometry; (b) compared to spirometry, the ISAAC questionnaire underestimated the prevalence of childhood asthma in Delhi by $34.5 \%$, but the difference was smaller in K-M; and (c) FEV1/FVC $<0.85$ seems to be an appropriate cut off value to define airflow obstruction among adolescent school children.

Over six million children reside in Delhi, which has the dubious distinction of being one of the most polluted cities in the world, with ambient particulate matter pollution levels exceeding the WHO standards by well over 15 fold. Earlier studies in school children from Delhi using questionnaires reported asthma prevalence rates between $4.6 \%$ and $15.7 \% .^{[6,13,14]}$ The only study (2007) that determined the prevalence of asthma using spirometry among children living in an industrialized locality of Delhi reported $11.2 \% .{ }^{[15]}$ Our study reports a very high prevalence of asthma among adolescent school children living in Delhi as compared to previous reports. We do not know whether air pollution is responsible for this increase, but it is indeed tempting to speculate that this may well be the case.

Contrary to our study hypothesis, the lung volumes on spirometry $\left(\mathrm{FEV}_{1}\right.$ and $\left.\mathrm{FVC}\right)$ were significantly higher in children living in Delhi compared to those living in K-M. Moreover, the prevalence of PRISm (restrictive impairment) was significantly higher among children living in K-M. While poorly performed spirometry is one of the most common causes of PRISm, we are confident that our quality of spirometry was good. One of the major strengths of our study was that the equipment, techniques, and quality assurance of spirometry were based on 
international standards and were identical across all sites, such that any difference in lung function cannot be attributed to methodological discrepancies. We used the latest ultrasonic flow sensor-based spirometer that stores all data and allows inspection of flow-volume loops and volume-time curves, which could be transmitted directly to the central quality assurance center. All staff were highly trained and were constantly supervised by team of experienced doctors. Low lung volumes and PRISm have been reported in Indian children living in the rural areas as compared to children living in urban areas. ${ }^{[16]}$ We selected K-M in South India because they were classified as urban cities with low ambient air pollution levels. However, urbanization in these cities has been relatively recent as compared to Delhi and a significant portion of K-M still continues to have a rural component. We believe that this factor may have strongly influenced the lung function differences that we noted between D and K-M in our study.
Although asthma in children is essentially a clinical diagnosis based on symptoms and risk factors, spirometry remains the gold-standard diagnostic test. The appropriate cutoff value for $\mathrm{FEV}_{1} / \mathrm{FVC}$ to define airflow obstruction/ asthma in children, has however, been a topic of recent debate. The National Institute of Clinical Excellence guidelines from the UK have recommended a cutoff value of $<0.70$ for children as well as adults. ${ }^{[17]}$ However, this cutoff value was challenged by Murray et al. ${ }^{[18]}$ from Manchester, the UK in 2017, who showed that it had a very low sensitivity of $2.7 \%$ to detect asthma in adolescent children. They reported that a cutoff value of $<0.83$ had the highest Youden's Index. Using the Swiss Paediatric Airway Cohort, de Jong et al. ${ }^{[19]}$ also reported very low sensitivity of $8 \%$ for the cutoff value of 0.7 , and more recently they reported that $<0.86$ was the most appropriate cut off value to define asthma in children. ${ }^{[20]}$ The Global Initiative for Asthma guidelines have always

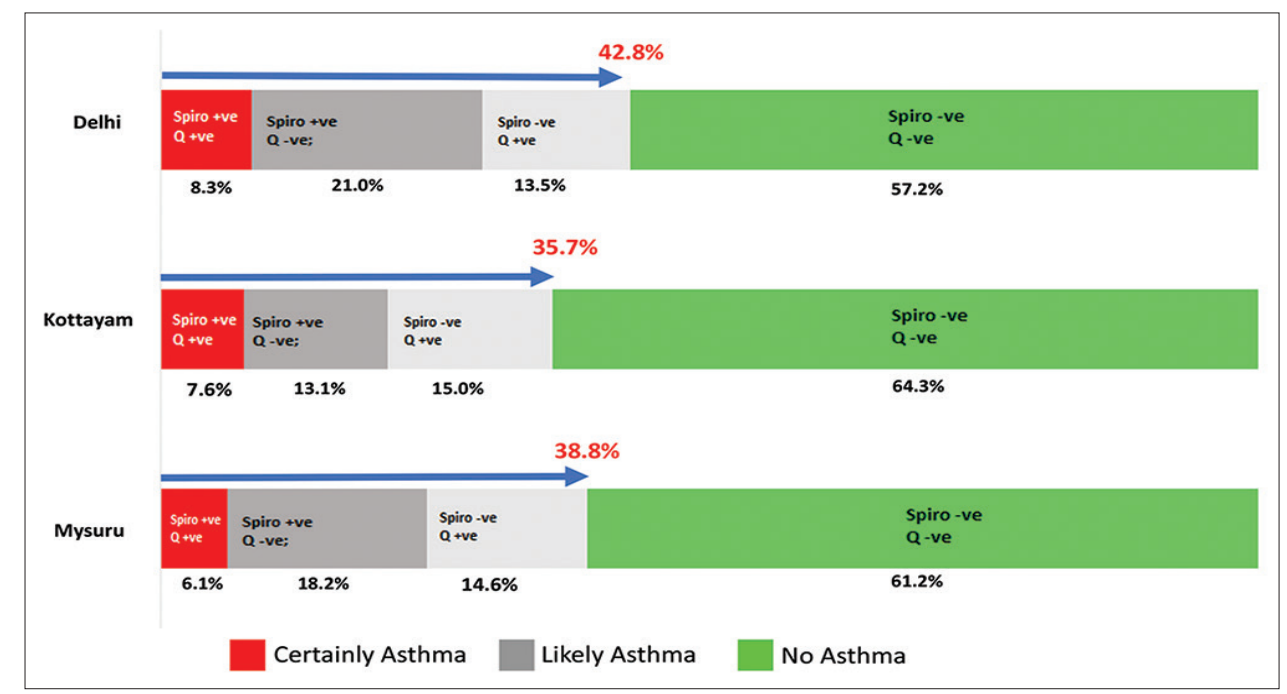

Figure 2: Differences in the burden of asthma using ISAAC $Q$ and Spirometry between D and K-M

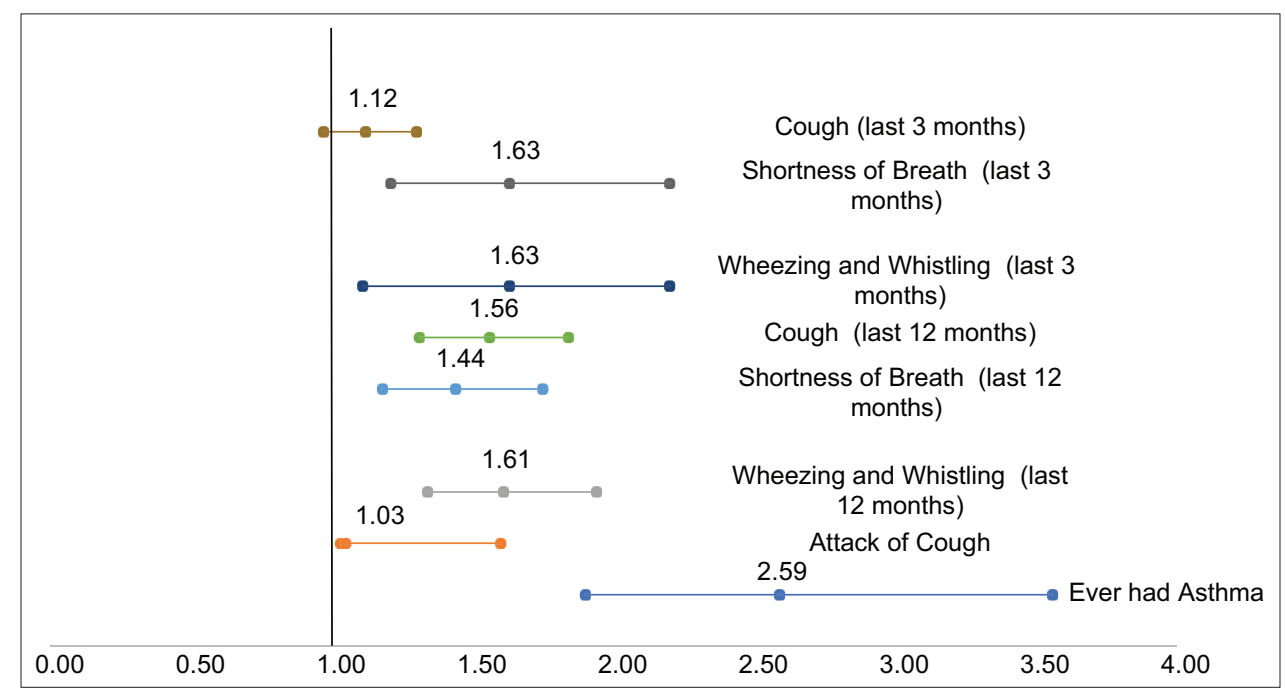

Figure 3: Association between asthma symptoms and forced expiratory volume1/Forced vital capacity $<0.85$ 
maintained a cutoff value of $<0.90^{[21]}$ to define airflow obstruction/asthma in children since 2002, but the two recent studies ${ }^{[18,20]}$ showed that although this cutoff value had very high sensitivity, the specificity was unacceptably low. Based on the studies by Murray et al. ${ }^{[18]}$ and de Jung et al., ${ }^{[20]}$ we used a cutoff value of $<0.85$ to define airflow obstruction/asthma in our adolescent study population. We further showed that this cutoff correlated strongly with asthma symptoms such as shortness of breath, wheeze, cough (12 m), attack of cough, and history of ever having asthma [Figure 3]. The observations made in our study, therefore, support the use of $\mathrm{FEV}_{1} / \mathrm{FVC}<0.85$ as the appropriate cutoff value to define airflow obstruction/ asthma in adolescent children.

Compared to spirometry, ISAAC Questionnaire underdiagnosed asthma in Delhi by $34.5 \%$. The ISAAC questionnaire focusses primarily on wheeze as the defining criteria for asthma. It is now well-known that wheeze alone does not predict the true asthma prevalence and the use of combination of symptoms is essential to yield a valid asthma symptoms prevalence. ${ }^{[22]}$ The prevalence of asthma was 2.4-fold higher among boys than girls, an observation that was consistent across all the three centers. Earlier studies ${ }^{[23]}$ reported that asthma is more common among boys than girls during childhood, which tends to start switching over during puberty. However, we did not observe such a transition in our study.

Children living in Delhi were not only taller and heavier but were 2.1-times more overweight and 3.3-times more obese than children living in K-M. Being overweight and obese was the only risk factor associated with spirometrically defined asthma in our study, whether analyzed overall, or even for each individual city. The effect was, however, more pronounced in children living in Delhi.

Over the past decade, a number of epidemiologic and animal studies have suggested the role of pre- and postnatal exposure to air pollutants as a cause for childhood obesity. ${ }^{[24-27]}$ Although no clear mechanisms have been elucidated, physical inactivity, systemic oxidative stress, chronic activation of the hypothalamo-pituitary-adrenal axis, change in gut bacterial flora and epigenetic modifications have been suggested as possible mechanisms by which air pollution causes obesity. ${ }^{[24]}$ Polyaromatic hydrocarbons which are combustion products of automobile exhausts act as endocrine-disrupting chemicals or obesogens that cause dysregulation of the hormonal network controlling appetite and endocrine tissues which changes insulin sensitivity and lipid metabolism. ${ }^{[28]}$ Childhood exposures to regional and traffic-related air pollutants have been shown to increase consumption of transfat and fast foods by adolescents, thereby contributing to obesogenic behavior. ${ }^{[29]}$

The association between obesity and asthma/wheezing is well established, and obesity is now recognized as a strong risk factor for childhood asthma both in developed and developing countries. ${ }^{[30]} \mathrm{A}$ recent study from the US reported that around $23 \%-28 \%$ of new asthma cases in children could be attributable directly to obesity. ${ }^{[31]}$ In a large ( $>10,000$ children aged 8-12 years), international, multicenter study including both affluent and nonaffluent countries, Weinmayr et al..$^{[32]}$ reported that excess weight was associated with asthmatic symptoms as well as eczema, rhinitis, and greater airflow obstruction on spirometry. More recently, obesity has been shown to further amplify the harmful effects of air pollution in children, ${ }^{[33]}$ thereby creating a vicious cycle between air pollution and obesity.

It is tempting to speculate that chronic exposure to high levels of air pollution in Delhi led to the development of higher BMI (overweight and obesity), which further enhanced the risk of developing asthma and allergic diseases.

Our study also showed that $88 \%$ of the children identified to have asthma in Delhi were not aware about their diagnosis and only $0.3 \%$ of them were using some form of inhalers. The figures for K-M were $73 \%$ and $8 \%$, respectively, indicating that asthma remains grossly underdiagnosed and undertreated overall in India and that Delhi fares relatively worse. Chhabra et al. ${ }^{[13]}$ reported almost exactly the same figures of underdiagnosis and undertreatment in Delhi 22 years ago, suggesting that things have not changed much over the last two decades.

\section{CONCLUSION}

In conclusion, adolescent school children living in the polluted city of Delhi were significantly more overweight and obese than children living in the cleaner South Indian cities of Kottayam and Mysore, accompanied by the higher prevalence of self-reported respiratory symptoms, allergic rhinoconjunctivitis, eczema, and spirometrically defined asthma, despite having better lung function values. Although we could not perform multiple logistic regression analysis with various air pollutants and health indices, including BMI, because of lack of adequate air pollution data from Kottayam and Mysore, it is tempting to speculate that chronic exposure to high levels of ambient air pollution increases BMI among urban adolescent children, which further enhances the development of asthma and allergic diseases. The association between air pollution, obesity and asthma among adolescent children in low- and middle-income countries needs to be explored further.

Acknowledgment

We would like to express our sincere thanks to:

- Dr G Siddesh, Senior Consultant Surgeon, Mysore and Dr Binni John, Senior Consultant Surgeon, Kottayam, for helping us in co-ordinating the study with the schools in Mysore and Kottayam

- Principals, Teachers, Staff Members, Parents and Children from participating schools in Delhi, Mysore, and Kottayam

Lung India • Volume 38 • Issue 5 • September-October 2021 
- Dr M.P. George from Delhi Pollution Control Committee and Officials from pollution control boards at Mysore and Kottayam for helping with Pollution data from their cities

- Team Lung Care Foundation consisting of Mr. Rajiv Khurana, Founder Trustee, Ms. Neha Tiwari and Ms. Sadhana, Nursing Officers, Dr. Trao Lenei, Project Coordinator, Ms. Matrushri P. Shetty, Director- Programs and Strategy, Ms. Kritika Sharma, Project Coordinator - BEST Clubs and Ms. Charu Dhingra, Director- Medical Programs for help in the conduct of this study.

Financial support and sponsorship

Shakti Sustainable Energy Foundation, India, for funding the study.

\section{Conflicts of interest}

There are no conflicts of interest.

\section{REFERENCES}

1. Singh V, Singh $S$, Biswal A. Exceedances and trends of particulate matter $\left(\mathrm{PM}_{2.5}\right)$ in five Indian megacities. Sci Total Environ 2021;750:141461.

2. Central Pollution Control Board, Ministry of Environment, Forest and Climate Change. National Ambient Air Quality Status and Trends; 2019. Available from: https://cpcb.nic.in/upload/NAAQS_2019.pdf. [Last accessed on 2020 Oct 28].

3. The Lancet Planetary Health. Government indifference over air pollution crisis in Delhi. Lancet Planet Health 2017;1:e348.

4. Salvi S. Health effects of ambient air pollution in children. Paediatr Respir Rev 2007;8:275-80.

5. Khreis H, Kelly C, Tate J, Parslow R, Lucas K, Nieuwenhuijsen M. Exposure to traffic-related air pollution and risk of development of childhood asthma: A systematic review and meta-analysis. Environ Int 2017; 100:1-31.

6. Siddique S, Ray MR, Lahiri T. Effects of air pollution on the respiratory health of children: A study in the capital city of India. Air Qual Atmos Health 2011;4:95-102.

7. Chhabra SK, Gupta CK, Chhabra P, Rajpal S. Risk factors for development of bronchial asthma in children in Delhi. Ann Allergy Asthma Immunol 1999;83:385-90

8. Gauderman WJ, Gilliland GF, Vora H, Avol E, Stram D, McConnell R, et al. Association between air pollution and lung function growth in southern California children: Results from a second cohort. Am J Respir Crit Care Med 2002;166:76-84.

9. Khafaie MA, Salvi SS, Yajnik CS, Ojha A, Khafaie B, Gore SD. Air pollution and respiratory health among diabetic and non-diabetic subjects in Pune, India-results from the Welcome Trust Genetic Study. Environ Sci Pollut Res Int 2017;24:15538-46.

10. Chhabra SK, Kumar R, Mittal V. Prediction equations for spirometry for children from northern India. Indian Pediatr 2016;53:781-5.

11. Miller MR, Hankinson J, Brusasco V, Burgos F, Casaburi R, Coates A, et al. Standardisation of spirometry. Eur Respir J 2005;26:319-38.

12. Haq I, Raja M, Ahmad M. A comparison of the 2015 Indian Academy of Pediatrics, International Obesity Task Force and World Health Organization growth references among 5-18-year-old children. Ann Trop Med Public Health 2017;10:1814-9.

13. Chhabra SK, Gupta CK, Chhabra P, Rajpal S. Prevalence of bronchial asthma in schoolchildren in Delhi. J Asthma 1998;35:291-6.

14. Singh S, Sharma BB, Sharma SK, Sabir M, Singh V, ISAAC collaborating investigators. Prevalence and severity of asthma among Indian school children aged between 6 and 14 years: Associations with parental smoking and traffic pollution. J Asthma 2016;53:238-44.

15. Kumar R, Nagar JK, Kumar H, Kushwah AS, Meena M, Kumar P, et al. Association of indoor and outdoor air pollutant level with respiratory problems among children in an industrial area of Delhi, India. Arch Environ Occup Health 2007;62:75-80.

16. Sonnappa S, Lum S, Kirkby J, Bonner R, Wade A, Subramanya V, et al. Disparities in pulmonary function in healthy children across the Indian urban-rural continuum. Am J Respir Crit Care Med 2015;191:79-86.

17. National Institute for Health and Care Excellence (NICE). Guideline Asthma Diagnosis and Monitoring. Available from: http://www.nice.org.uk/guidance/ng80/evidence/ full-guideline-asthma-diagnosis-and-monitoring-pdf-4656178047. [Last accessed on 2020 Oct 14, Last updated on 2020 Sep 21].

18. Murray C, Foden P, Lowe L, Durrington H, Custovic A, Simpson A. Diagnosis of asthma in symptomatic children based on measures of lung function: An analysis of data from a population-based birth cohort study. Lancet Child Adolesc Health 2017;1:114-23.

19. de Jong CC, Pedersen ES, Mozun R, Goutaki M, Trachsel D, Barben J, et al. Diagnosis of asthma in children: The contribution of a detailed history and test results. Eur Respir J 2019;54:1901326.

20. de Jong CC, Pedersen ES, Mozun R, Müller-Suter D, Jochmann A, Singer $F$, et al. Diagnosis of asthma in children: Findings from the Swiss Paediatric Airway Cohort. Eur Respir J 2020;56:2000132.

21. Global Strategy for Asthma Management and Prevention. Global Initiative for Asthma; 2020. p. 23. Available from: https://ginasthma. org/wp-content/uploads/2020/04/GINA-2020-full-report_final-_wms. pdf. [Last accessed on 2020 Oct 14].

22. Magzoub AA, Musa OA, Elsony AE, Alawad AO, Dawod OY. Validation of the Modified International Study of Asthma and Allergies in Childhood questionnaire: Is wheeze alone enough for determination of asthma symptoms prevalence? Int J Med Sci Public Health 2017;6:775-8.

23. Vink NM, Postma DS, Schouten JP, Rosmalen JG, Boezen HM. Gender differences in asthma development and remission during transition through puberty: The TRacking Adolescents' Individual Lives Survey (TRAILS) study. J Allergy Clin Immunol 2010;126:498-504.e1.

24. Seo MY, Kim SH, Park MJ. Air pollution and childhood obesity. Clin Exp Pediatr 2020;63:382-8.

25. Wang Z, Zhao L, Huang Q, Hong A, Yu C, Xiao Q, et al. Traffic-related environmental factors and childhood obesity: A systematic review and meta-analysis. Obes Rev 2021;22 Suppl 1:e12995.

26. Jerrett M, McConnell R, Wolch J, Chang R, Lam C, Dunton G, et al. Traffic-related air pollution and obesity formation in children: A longitudinal, multilevel analysis. Environ Health 2014;13:49.

27. Wei Y, Zhang JJ, Li Z, Gow A, Chung KF, Hu M, et al. Chronic exposure to air pollution particles increases the risk of obesity and metabolic syndrome: Findings from a natural experiment in Beijing. FASEB J 2016;30:2115-22.

28. Heindel JJ, Newbold R, Schug TT. Endocrine disruptors and obesity. Nat Rev Endocrinol 2015;11:653-61.

29. Chen Z, Herting MM, Chatzi L, Belcher BR, Alderete TL, McConnell R, et al. Regional and traffic-related air pollutants are associated with higher consumption of fast food and trans fat among adolescents. Am J Clin Nutr 2019;109:99-108.

30. Forno E, Celedón JC. The effect of obesity, weight gain, and weight loss on asthma inception and control. Curr Opin Allergy Clin Immunol 2017;17:123-30.

31. Lang JE, Bunnell HT, Hossain MJ, Wysocki T, Lima JJ, Finkel TH, et al. Being overweight or obese and the development of asthma. Pediatrics 2018;142:e20182119.

32. Weinmayr G, Forastiere F, Büchele G, Jaensch A, Strachan DP, Nagel G, et al. Overweight/Obesity and Respiratory and Allergic Disease in Children: International Study of Asthma and Allergies in Childhood (ISAAC) Phase Two. PLoS One 2014;9:E113996.

33. Permaul P, Gaffin JM, Petty CR, Baxi SN, Lai PS, Sheehan WJ, et al. Obesity may enhance the adverse effects of $\mathrm{NO}_{2}$ exposure in urban schools on asthma symptoms in children. J Allergy Clin Immunol 2020;146:813-20.e2. 
Supplementary Table 1: Details of study participants

\begin{tabular}{lccc}
\hline & Delhi, $\boldsymbol{n} \mathbf{( \% )}$ & Kottayam, $\boldsymbol{n}(\mathbf{\%})$ & Mysore, $\boldsymbol{n}(\mathbf{\%})$ \\
\hline Number of schools randomized & 3 & 6 & 3 \\
Number of children approached (years) & 1484 & 1379 & 1498 \\
13-14 & $667(44.9)$ & $686(49.7)$ & $616(41.1)$ \\
6-17 & $817(55.1)$ & $693(50.3)$ & $882(58.9)$ \\
Number of children who consented & $1026(69.1)$ & $1154(83.7)$ & $1276(85.2)$ \\
Number of children who completed the Q's & $1019(68.7)$ & $1154(83.7)$ & $114(8.3)$ \\
Number of rejected spirometry reports & $91(6.1)$ & $1040(75.4)$ & $72(84.2)$ \\
Completed Q's + acceptable spirometry's & $928(62.5)$ & 1040 & $1189(79.4)$ \\
Final analysable data & 928 & $405(38.9)$ & 1189 \\
Boys & $506(54.5)$ & $635(61.1)$ & $683(57.4)$ \\
Girls & $422(45.5)$ & $497(47.8)$ & $506(42.6)$ \\
13-14 years & $438(47.2)$ & $543(52.2)$ & $548(46.1)$ \\
16-17 years & $490(52.8)$ & & $641(53.9)$ \\
\hline
\end{tabular}

Supplement Table 2: Comparison for the prevalence of asthma using spirometry (forced expiratory volume ${ }_{1} /$ forced vital capacity $<0.85$ ) and (international study on asthma and allergy) criteria

\begin{tabular}{lcccc}
\hline & $\boldsymbol{n}$ & $\begin{array}{c}\text { Spirometry defined asthma } \\
\left(\text { FEV }_{\mathbf{1}} / \mathbf{F V C}<\mathbf{8 5 \% )}\right.\end{array}$ & $\begin{array}{c}\text { ISAAC defined } \\
\text { asthma (\%) }\end{array}$ & $\begin{array}{c}\mathbf{9 5 \%} \text { CI of difference } \\
\text { (lower-upper) }\end{array}$ \\
\hline Delhi & 928 & 29.31 & 21.77 & $3.50-11.40$ \\
Kottayam & 1040 & 20.67 & 22.60 & $-1.61-5.46$ \\
Mysore & 1189 & 24.22 & 20.61 & $0.26-6.95$ \\
Delhi + Kottayam + Mysore & 3157 & 24.55 & 21.60 & 0.312 \\
\hline FEV & P & $0.87-5.03$ & 0.038 \\
\hline
\end{tabular}

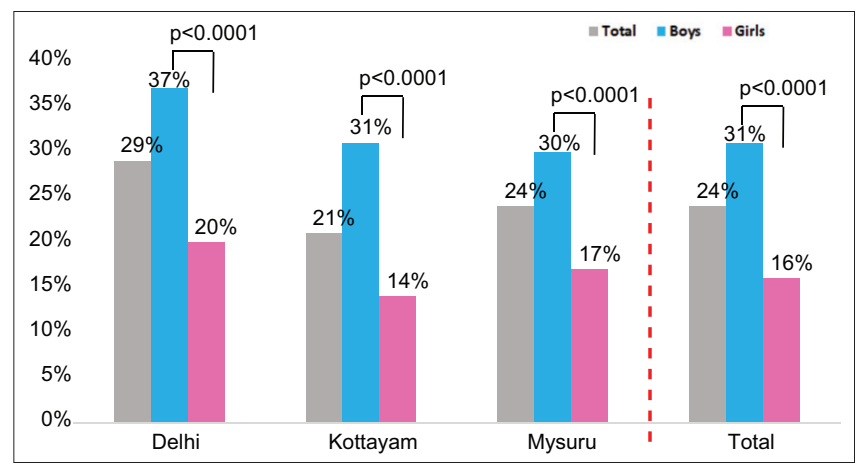

Supplement Figure 1: Differences in the prevalence of asthma between boys and girls 